\title{
Alfabetización visual crítica y educación en lengua materna: estrategias metacognitivas en la comprensión lectora de textos multimodales ${ }^{1}$
}

\section{Critical visual literacy and education in mother tongue: Metacognitive strategies in the reading comprehension of multimodal texts}

\author{
Miguel Farías, Ph.D. \\ Universidad de Santiago de Chile \\ Santiago de Chile, Chile \\ miguelfariasf@gmail.com \\ Claudio Araya Seguel, M.A. \\ Universidad de Santiago de Chile \\ Santiago de Chile, Chile \\ clauraya28@gmail.com
}

http://dx.doi.org/10.14483/udistrital.jour.calj.2014.1.a08

Received: 9-Aug-2013 / Accepted: 16-Dic-2013

To cite this article

Farías, M. \& Araya, C. (2014). Alfabetización visual crítica y educación en lengua materna: estrategias metacognitivas en la comprensión lectora de textos multimodales. Colombian Applied Linguistics Journal, 16(1), 93-104.

\section{Resumen}

En el contexto del cambiante paisaje sociosemiótico de interacciones discursivas de hoy, en este trabajo esbozamos un programa de alfabetización visual crítica de textos multimodales para la educación en lenguas. Exponemos un análisis de un texto multimodal desde dos modelos semióticos y evaluamos sus posibilidades de exploración en procesos de significación. El primero, Magariños (1991), propone una amplia lectura visual a partir de nueve relaciones entre forma, existencia y valor; el segundo, Kress y van Leeuwen (1996), adscrito a la semiótica discursiva, descompone el espacio visual en áreas que articulan lo ideal, lo real, lo dado y lo nuevo en el diseño textual. Los resultados indican que el modelo de Magariños resulta más efectivo en la exploración de los signos y las amplias significaciones culturales plasmadas en los textos multimodales; en tanto, el de Kress y van Leeuwen ofrece mayores posibilidades de indagación de la estructura y organización del diseño y las relaciones entre texto imagen en textos multimodales. La aplicación de estos modelos permite evaluar las potencialidades didácticas de la alfabetización visual crítica y sus contribuciones al desarrollo tanto de nuevas competencias de pensamiento crítico de estudiantes como de innovadoras estrategias pedagógicas en la enseñanza y aprendizaje de lenguas.

Palabras clave: alfabetización visual, textos multimodales, modelos sociosemióticos, nuevas alfabetizaciones.

\begin{abstract}
In the context of today's changing sociosemiotic landscape of discourse interactions, in this paper we outline a proposal for critical visual literacy of multimodal texts in language education. Two models are used to analyze a single text; the first one, Magariños (1991), offers the possibilities for thorough visual readings in nine relations that encompass form, existence and value. The other, a sociosemiotic model by Kress and van Leeuwen (1996), breaks down the visual space into four quadrants that account for the ideal, real, new and given dimensions in the design of multimodal discourse. Results indicate that Magariños' model proved to be more effective in exploring signs and their overarching cultural meanings, as constructed in
\end{abstract}

1 Este trabajo es resultado parcial del proyecto DICYT 031351FF, Universidad Santiago de Chile. 
multimodal texts. In turn, Kress and van Leeuwen's offered more possibilities for the analysis of the structure and organization underlying the design and text-image relations in multimodal texts. Through the application of these models it was possible to evaluate the pedagogical potential of critical visual literacy and its contribution to develop new competences that aim at both raising learners' critical thinking and fostering new strategies in language learning and teaching.

Keywords: visual literacy, multimodal texts, sociosemiotic models, new literacies.

\section{Introducción}

Uno de los problemas fundamentales que deben enfrentar los educadores en las áreas del lenguaje (sea lengua materna, extranjera o indígena) es la lectura de imágenes, sobre todo en textos del ámbito de la publicidad, la propaganda, el cine y, en el último tiempo, en las plataformas comunicacionales de internet que hacen posible interacciones como el chat, el correo electrónico, Skype, blogs, Facebook y Twitter y las variadas posibilidades discursivas que ellas brindan a los usuarios.

Es indudable que como profesores de lenguas nos vemos enfrentados a textos que difieren en gran medida de los textos con los cuales nosotros aprendimos a leer y escribir. Estas diferencias no son solo generacionales (que marcan la diferencia entre la generación "de página" y la "de pantalla" -page to screen, Turkle, 1995) sino que, con el rápido avance de las TICs, son también intra generacionales y requieren de nuevos modelos o de explicaciones emergentes realizadas colaborativamente con los usuarios.

Un hito importante en esta discusión es el encuentro del grupo denominado New London donde se revisó y propuso un conjunto de nuevas destrezas y competencias en el manejo de las comunicaciones necesarias para la sobrevivencia en los cambiantes escenarios epistemológicos del mundo de hoy] (Cope EKalantzis, 2000). Uno de los cambios importantes que emergió del trabajo del grupo de New London es la pluralización del concepto de alfabetización (o lecto-escritura) para incluir otras competencias como las alfabetizaciones televisiva, computacional, digital, visual. Esta última alfabetización es particularmente de urgente interés en el aprendizaje de lenguas $\mathrm{y}$, por tanto, en la formación de profesores de lenguas, tomando en cuenta, por una parte, que los textos cada vez más combinan imágenes y texto y, por otra, que la lectura en pantalla ha pasado a ser un hábito en la vida de ciudadan@s del siglo 21.
En este trabajo presentamos una breve introducción a una metodología de alfabetización visual que puede ser usada por profesores de lenguas y en la formación de profesores de lenguas con distintos textos multimodales de los ámbitos propios de cada contexto educativo. Esta metodología forma parte de un proyecto de investigación que tiene como objetivos explorar el potencial de los textos multimodales en la comprensión de lectura y diseñar estrategias metodológicas que apunten al desarrollo de la alfabetización visual crítica en la lectura de textos multimodales en lengua materna.

\section{Antecedentes teóricos}

La creciente importancia que cobra la dimensión visual en la presentación de la lengua ha generado la creación de textos multimodales que requieren formas distintas de abordaje (Kress, 2003), diferentes a los modelos tradicionales de explicación de los procesos de lectura y escritura de textos Walsh, 2006). El desarrollo de habilidades de creación e interpretación visual es y será requisito para un desempeño social eficiente, como Kress y van Leeuwen (1996)lo adelantaron:

Creemos que la comunicación visual es cada vez menos del dominio de especialistas y cada vez es más crucial en los dominios de la comunicación pública. [...] No ser 'visualmente alfabeto empezará a traer sanciones sociales. La 'alfabetización visual' pasará a ser una cuestión de sobrevivencia, particularmente en el mundo laboral. (p.3)

Sin embargo, en el cambiante contexto de creación de intersubjetividades (Farías, 2008) característico de las comunicaciones de fines del s. 20 y comienzo del s. 21, el concepto de nuevas alfabetizaciones puede ser abordado desde dos categorías (complementarias), como los señalan Lankshear y Knobel en Farías y Orrego (2008): 
[...] reconocemos dos amplias categorías de las nuevas alfabetizaciones. La primera categoría, las que hemos identificado como nuevas alfabetizaciones post tipográficas, es muy conocida, aunque no sea a menudo particularmente muy bien definida o entendida. Estas son alfabetizaciones asociadas con nuevas tecnologías de la información y comunicaciones o, en términos generales, con dispositivos digitales (Ulmer 1987). La segunda categoría es una categoría más suelta y más ad hoc que comprende alfabetizaciones que son comparativamente nuevas en términos cronológicos y/o que son o serán reconocidas como nuevas alfabetizaciones -aún desde una perspectiva sociocultural. Las alfabetizaciones en esta segunda categoría pueden tener poco o nada que ver con el uso de (nuevas) tecnologías digitales electrónicas. En algunos casos, no obstante, muy bien podrían contener nuevas tecnologías por derecho propio (p.2572).

Podemos incluir en esta segunda categoría, como ejemplos, la alfabetización cívica y la alfabetización ecológica, que podrían requerir del uso de la TICs pero que también se pueden desarrollar de manera independiente. La alfabetización visual si bien requiere y está referida en estos días principalmente a textos multimodales en soporte digital, también se puede desarrollar como una competencia independiente de las TICs, con fines de apreciación estética y crítica. La alfabetización visual ha sido definida por Braden y Hortin (1982), quienes sostienen que es "la capacidad de entender y usar imágenes, incluyendo la capacidad de pensar, aprender y expresarse en términos de imágenes" (1982:169). Por su parte, Bamford (2007) la concibe como un constructo que implica una serie de habilidades para interpretar los contenidos de las imágenes y además habilidades que involucren los impactos sociales que ellas generan, sus propósitos, las audiencias que están expuestas y quiénes son los productores de esas imágenes. Esta última aproximación al concepto de alfabetización visual va en consonancia con los tres objetivos (mencionados en el apartado 2.2) que respaldan la aplicación de las estrategias que se proponen en este trabajo.

Cabe, entonces, preguntarse qué se hace en Latinoamérica ante este panorama de cambios en los for- matos de presentación de la lengua y de pluralización del concepto de alfabetización. Podemos mencionar que, en Argentina, Loyo (2001) plantea una propuesta constructivista de comprensión de textos e hipertextos en entornos de colaboración vía redes telemáticas. En Colombia, Clavijo y Quintana, 2004; Clavijo, Quintana y Quintero, 2011; Hernández y Quintero, 2005; Rueda y Quintana, 2007 han explorado los fundamentos de la introducción de la cultura informática en el sistema escolar, con particular atención en el desarrollo de una pedagogía crítica centrada en redes de colaboración. Otros investigadores colombianos, Barragán y Gómez (2012) constatan la estrecha y desvalorizada definición que existe del lenguaje visual en el ámbito educativo y proponen un modelo didáctico centrado en el análisis de la caricatura. Ilustran la complejidad de la lectura de caricaturas donde se evidencia el tránsito de un análisis retórico de la imagen a uno que exige vincular lo leído con el contexto. Por su parte, en Chile, Pereira y González (2011) critican la falta de herramientas que permitan describir desde una perspectiva multimodal los textos escolares y presentan el Modelo Multimodal de Análisis Descriptivo (MADETEC) con el fin de analizar el rol y tipo de imágenes empleadas en los textos escolares y su articulación con los diversos géneros escritos.

Podemos agregar que en Chile se incorporan expresamente en el currículo de Lenguaje y Comunicación para enseñanza primaria y secundaria la comunicación visual y el análisis de mensajes multimodales. Sin embargo, la comprensión de lectura sigue anclada a los textos tradicionales lingüísticos, por lo cual, es en esta dimensión del proceso de enseñanza aprendizaje donde se podrían -eventualmente- advertir debilidades desde el punto de vista de la preparación del profesorado y de los mecanismos evaluativos (Muñoz, 2008) empleados para verificar el grado de comprensión de textos de naturaleza visual. En este sentido, la educación debe -sin duda- acoger este cambio de paradigma epistemológico, pues le compete incorporar, reflexionar y evaluar el nuevo paisaje en el que están insertos y donde son participantes activos los estudiantes.

Desde una perspectiva crítica conviene señalar que una vez más las prácticas educativas latinoamericanas parecen ir a la saga de las innovaciones que requieren los cambios del panorama intelectual contemporáneo. Por ejemplo, ya Australia integra en 
su sistema de medición de las habilidades lectoras, la dimensión semiótica en su National Assessment Program Literacy and Numeracy (NAPLAN) lo cual tiene un desarrollo simultáneo con avances en la investigación de las relaciones entre texto e imagen en textos multimodales (Unsworth 2006, 2008; Martinec y Salway, 2005).

En general, se detecta un retraso en la integración de los nuevos textos multimodales en el sistema educativo, reconocido por una de las figuras señeras en la articulación de modelos sociosemióticos de procesamiento discursivo. A saber, Kress (en entrevista con Farías, 2008) señala:

Si la educación se trata de aprendizaje y si creamos significados en varios modos de manera tal que nuestro compromiso con el mundo es siempre multimodal, entonces parece simplemente esencial que la institución encargada de los aprendizajes esté no solo basada en el aprendizaje de la lengua sino en cómo la cultura que se le presenta a los niños en la escuela está representada y como los jóvenes hacen sentido de ella. Eso no se puede hacer solo por medio de una pedagogía basada en lo lingüístico. (p.17)

Es también necesario mencionar que de la misma manera como se generó al interior de los Estudios del Discurso un movimiento particular denominado Análisis Crítico del Discurso (Van Dijk. 1999; Fairclough \& Wodak, 2001) orientado a develar los abusos y discriminaciones ejercidos por medio del discurso, el estudio de la dimensión visual debería incluir también un abordaje crítico. Tal enfoque crítico utiliza los modelos sociosemióticos (Kress, 1997; Kress, 2003; Kress \& van Leeuwen, 2001) con el fin de dar cuenta de las motivaciones e intereses socioculturales, políticos e ideológicos en el diseño, producción y difusión de los discursos multimodales, situando la producción discursiva como práctica social motivada (Kress, Leite-García, van Leeuwen, 2001).

Cabe mencionar dentro de esta contextualización teórica que desde la filosofía han surgido voces que cuestionan el rol que ha desempeñado el lenguaje materializado en el discurso tradicional en el desarrollo y difusión del pensamiento y el conoci- miento. Zamora (2006) sostiene que la filosofía ha sido históricamente una disciplina logocéntrica que no ha sido capaz de explorar las nuevas formas que vehiculan el conocimiento, como son aquellas que han surgido al alero del desarrollo y consolidación de las tecnologías de la información y la comunicación. En esta línea, dicho autor reconoce la importancia de ir más allá de los enfoques de análisis semióticos y multimodales, y orientar la mirada en la gestación de una epistemología de la imagen que se desplace a lo que podríamos denominar iconocentrismo y que ofrezca un equilibrio a la tendencia logocéntrica dominante.

Esta mirada filosófica a los procesos de adquisición, desarrollo y difusión del conocimiento, sin duda, refuerza el impulso por examinar los emergentes procesos de lectura y comprensión gestados en las últimas décadas los que -además- se han ido articulando fuera de la institucionalidad académica convencional (Gee, 2004).

Los modelos de lectura visual que se exponen más adelante se aplican -en este trabajo- a un texto multimodal que forma parte del ámbito publicitario. Por esta razón es conveniente examinar -aunque sea brevemente- algunas ideas que permiten distinguir la publicidad de la propaganda.

\section{Publicidad y propaganda}

Es común observar que los estudiantes emplean indistintamente los términos propaganda y publicidad para referirse a la promoción de determinados productos, bienes o servicios. Sin embargo, según Lomas (1994), no son equivalentes pues, a pesar de corresponder a dos formas de comunicación, se fundan en motivaciones y objetivos distintos.

La propaganda busca difundir ideas filosóficas, religiosas, políticas o sociales, vale decir, opera en el ámbito ideológico; mientras que la publicidad obedece a motivaciones comerciales o económicas vinculadas al consumo de ciertos productos, bienes o servicios disponibles en el mercado.

Según Méndiz Noguero (2007) la diferencia no se reconoce tanto en los contenidos como en el método. Este autor sostiene: 
La Propaganda tiene algo de violento; es la ideología, el discurso cerrado y la proclamación de eslóganes sin discusión racional, sin atender a la realidad ni a los sentimientos; es la idea que se antepone a la persona. Por eso es el lenguaje de los imperativos categóricos (de un lado y del otro: fundamentalismo religioso o lo políticamente correcto); algo que no se discute: o lo aceptas o te autoexcluyes. La Publicidad, en cambio, es el terreno de la suavidad, de la seducción, del enamoramiento; es el arte y la estética, frente a la ideología; la comunicación y el diálogo, frente a la convicción; la retórica y el ingenio frente a la imposición. Por eso se mueve en el terreno de los mitos: no argumenta, sugiere; no impone, propone; no demuestra, sino que muestra con suavidad y sutileza. Méndiz Noguero, 2007, p. 57)

De este modo, se postula que la propaganda opera como una imposición que no deja espacios de discusión y se acuña el concepto de imperativos categóricos. En ella actúa la dimensión ideológica. En cambio, la publicidad es vinculada con la seducción verbal, pues reconoce la relevancia de las sugerencias retóricas y del ingenio en la construcción de los mensajes, es decir, se reconoce en ella la dimensión estética. Si como profesores de lengua estamos empeñados en formar estudiantes y futuros ciudadanos críticos, este objetivo nos obliga a cuestionar esta distinción al observar hoy en día la supremacía de un penetrante modelo ideológico neocapitalista que, por ejemplo, impone marcas a destajo (Klein, 2002). La publicidad no solo se encarga de difundir productos, bienes o servicios, que están a disposición del público en el mercado, sino que se propone fundamentalmente promover valores sociales, estilos de vida, concepciones del ser humano, todo lo cual conforma una visión de mundo; por lo tanto, circunscribir el aspecto ideológico solo a la propaganda parece ciertamente sesgado e inapropiado para un programa de alfabetización visual crítica basado en modelos sociosemióticos, con el que aquí se propone.

Como sea, ambas manifestaciones comunicativas intentan influir (persuadir) al receptor en beneficio del emisor y son productos discursivos originados en el poder. En los planes y programas del Ministerio de Educación de Chile (MINEDUC) de la asignatura Lenguaje y Comunicación se distinguen la publicidad de la propaganda a partir de la intencionalidad. De acuerdo con esto, la publicidad obedece a motivaciones comerciales y la propaganda apunta a aspectos ideológicos.

Por tanto, las intencionalidades constituyen un aspecto diferenciador de ambos conceptos. Al respecto sostiene Pineda Cachero:

Lo importante es que más allá de las designaciones terminológicas propaganda y publicidad se puedan distinguir con claridad dos conceptos (explicables por causas histórico-genéticas distintas y movidos por intenciones distintas), de la misma manera que podemos distinguir comunicaciones destinadas a informarnos sobre el clima o a provocarnos una experiencia estética. La publicidad responde a la intención de las empresas comerciales de vender sus productos y servicios, y/o implantar sus marcas en la sociedad. $\mathrm{Y}$ es en ese terreno donde deben dilucidarse sus diferencias con las manifestaciones propagandísticas generadas por las instancias de poder. En definitiva, establecer la diferencia entre propaganda y publicidad en función de un criterio intencional implica, desde un punto de vista comunicacional, desplazar la atención desde el mensaje o el receptor hacia el emisor. (2007, p. 124)

Sea cual sea el criterio para distinguir ambas manifestaciones comunicativas, lo cierto es que la hegemonía del sistema económico neoliberal (Klein, 2002) y su influencia en el plano político, trasforman las fronteras entre publicidad y propaganda en un campo difuso y, por tanto, el valor de imperativo categórico o políticamente correcto asignado a la propaganda basada en intenciones de bien común, se ha trasladado a la publicidad (Araya, 2011). De todas maneras, la producción discursiva tanto de publicidad como de propaganda puede ser abordada por estrategias de alfabetización visual crítica, anclada a modelos socio semióticos, como la que se propone a continuación. 


\section{Estrategias de alfabetización visual}

Como hemos mencionado en otro trabajo (Farías y Orrego, 2008) estas estrategias están motivadas por tres objetivos: que los estudiantes puedan, a) reflexionar de manera crítica sobre el poder de los textos multimodales y comprender que la construcción de textos no es una actividad neutral, b) asumir una conciencia retórica como productores y lectores de textos, y c) desarrollar la participación activa como comunicadores y no solo como receptores pasivos de mensajes mediáticos.

El involucramiento sociocognitivo de estudiantes y educadores en el desarrollo e implementación de estas estrategias debe estar no solo férreamente basado en la pedagogía crítica (Freire, 1970) sino también orientado a crear comunidades de interés y práctica, como lo señala Wenger (2007):

Lo que parece promisorio son las maneras inventivas de involucrar a los estudiantes en prácticas significativas, de ofrecerles acceso a recursos que fortalezcan su participación, de abrirles sus horizontes de manera que se puedan ubicar en trayectorias de aprendizaje con las cuales se puedan identificar, y de involucrarlos en acciones, discusiones y reflexiones que marquen una diferencia en las comunidades que ellos valoran. (p.10)

\section{Modelo de Magariños-Peirce}

En la obra Curso de Lingüística General, el lingüista ginebrino reconocido como el fundador de los estudios lingüísticos contemporáneos, Ferdinand de Saussure, propone un concepto dicotómico del signo y lo define como una entidad psíquica constituida por un significante y un significado, vale decir, una imagen acústica y una imagen mental, concepto o idea que se evoca cuando alguien produce una secuencia de sonidos determinada (Saussure, 1945). Sin embargo, Saussure se refiere fundamentalmente al signo lingüístico en el marco de las lenguas y no se refiere a los signos que no forman parte del sistema lingüístico; eso sí, reconoce que otra disciplina distinta de la lingüística debería ocuparse del funcionamiento de los signos en el marco de la vida social, y a esta disciplina la denominó semiología (Saussure, 1945).

Por su parte, Charles Sanders Peirce, propone un concepto de signo más complejo que el del lingüista gi- nebrino. Según Peirce, el signo es "Algo que se encuentra para Alguien en lugar de Algo, según cierta Relación o capacidad" (Sexe, 2004, p. 43). De acuerdo con esta definición, el signo puede considerarse un proceso constante en el cual existe una forma perceptual denominada representamen, un aspecto de objeto ya conocido o fundamento y una propuesta de nuevo conocimiento o interpretante. Estas distinciones hacen surgir algunas preguntas de análisis: mediante qué forma, qué existencia captura, interpretada según qué valores. De manera que el concepto de signo de Peirce nos permite captar formas, existencias y valores mediante formas, existencias y valores. Estas relaciones dieron lugar a un sistema diseñado por Magariños de nueve signos aplicables al análisis de avisos publicitarios u otros géneros discursivos y que se explicita en la Figura 1.

De estos nueve signos posibles, Cualisigno, Icono y Rhema corresponden a referencialidad icónica donde forma, existencia y valor son representados de manera denotativa. Otros tres, Sinsigno, Indice y Dicisigno, son de referencialidad indicial por medio de los cuales forma, existencia y valor adoptan un medio para su expresión. En tanto, Legisigno, Símbolo y Argumento, conllevan a referentes simbólicos donde forma, existencia y valor son interpretados connotativamente.

\section{Modelo de Kress, Leite - Garcia, Van Leeuwen}

Desde la perspectiva de la Semiótica Social se sostiene que las formas de significación, los modos y medios empleados para producirlos y que permiten configurar un diseño (Williamson, 2005), son actividades sociales que se enmarcan en el campo de la política, de las estructuras de poder y, por tanto, sometidas a los distintos intereses de los que producen textos.De ahí que se justifique plantear la idea del análisis crítico multimodal que hemos mencionado. Al respecto Kress, Leite-Garcia \& Van Leeuwen, (2001) sostienen:

Partimos del supuesto de que los intereses de quien produce un signo llevan a una relación motivada entre significante y significado y, por lo tanto, a signos motivados. Quien produce un signo trata de generar la representación más apropiada de lo que quiere significar. Por eso el interés del que hace signos está directamente cifrado en los medios de representación y comunicación (Kress, Leite-García E Van Leeuwen, 2001, p. 375) 


\begin{tabular}{|c|c|c|c|}
\hline \multirow{6}{*}{ FORMA } & FORMA & EXISTENCIA & VALOR \\
\hline & Ícono Icónico & Ícono Indicial & Ícono simbólico \\
\hline & CUALISIGNO & ÍCONO & RHEMA \\
\hline & Forma de la forma & Existencia de la forma & Valor de la Forma \\
\hline & $\begin{array}{l}\text { Aspectos visuales o acústicos } \\
\text { del mensaje publicitario como } \\
\text { totalidad }\end{array}$ & $\begin{array}{l}\text { Las formas visuales o acústicas } \\
\text { de objetos y comportamientos } \\
\text { concretamente representados }\end{array}$ & $\begin{array}{l}\text { La representación de percepciones sen- } \\
\text { soriales diferentes a las acústicas o visua- } \\
\text { les, relativas a los objetos y comporta- } \\
\text { mientos representados }\end{array}$ \\
\hline & Los colores de la pieza gráfica & Los elementos representados & Representación visual de un sonido \\
\hline \multirow{6}{*}{ EXISTENCIA } & FORMA & EXISTENCIA & VALOR \\
\hline & Índice Icónico & Índice Indicial & Indice simbólico \\
\hline & SINSIGNO & ÍNDICE & DICISIGNO \\
\hline & Forma de la existencia & Existencia de la existencia & Valor de la existencia \\
\hline & $\begin{array}{l}\text { Representación de la forma de } \\
\text { existir de los objetos, los acon- } \\
\text { tecimientos, las conductas }\end{array}$ & $\begin{array}{l}\text { Objetos, acontecimientos y } \\
\text { conductas que representan a } \\
\text { otros objetos, acontecimientos } \\
\text { y conductas con los que están } \\
\text { inmediatamente vinculados }\end{array}$ & $\begin{array}{l}\text { La representación de todo lo que cons- } \\
\text { tituya el contexto de una representación } \\
\text { determinada }\end{array}$ \\
\hline & $\begin{array}{l}\text { Lo que se muestra a través de } \\
\text { la fotografía }\end{array}$ & El envase de un producto & Contexto de un signo \\
\hline \multirow{6}{*}{ VALOR } & FORMA & EXISTENCIA & VALOR \\
\hline & Símbolo Icónico & Símbolo Indicial & Símbolo Simbólico \\
\hline & LEGISIGNO & SÍMBOLO & ARGUMENTO \\
\hline & Forma del Valor & Existencia del Valor & Valor del Valor \\
\hline & $\begin{array}{l}\text { Las formas por las cuales se } \\
\text { reconoce un determinado len- } \\
\text { guaje }\end{array}$ & $\begin{array}{l}\text { Un determinado lenguaje en } \\
\text { cuanto portador de contenidos } \\
\text { específicos }\end{array}$ & $\begin{array}{l}\text { La representación de los valores sociales } \\
\text { vigentes en determinada comunidad }\end{array}$ \\
\hline & $\begin{array}{l}\text { Connotaciones a través de la } \\
\text { Tipografía. }\end{array}$ & $\begin{array}{l}\text { El significado atribuíble a lo re- } \\
\text { presentado. La semantización } \\
\text { implícita que se propone al re- } \\
\text { ceptor. }\end{array}$ & $\begin{array}{l}\text { Los valores sociales y/o culturales que se } \\
\text { representan en el mensaje }\end{array}$ \\
\hline
\end{tabular}

Figura 1. Modelo de Magariños (1991)

Si se establece una relación entre los signos creados y los intereses de quienes los producen, queda en evidencia el carácter motivado de esos signos, lo que contradiría la visión tradicional de signo saussureano que hemos reseñado y que se asocia a un sistema abstracto de la lengua. Consecuentemente, dado que los significados de esos signos motivados se enmarcan en el campo de la política y de las estructuras de poder, se hace necesario una exploración de la dimensión ideológica y, por tanto, se requiere un modelo de semiótica (semiología en la temprana tradición europea) social contextualizado (Kress, 2000).

Desde la perspectiva multimodal, cada discurso es concebido como un dispositivo comunicativo complejo y esta complejidad puede obedecer al tipo de lectura que nos propone: ya no podemos leer de izquierda a derecha, de forma más o menos convencional, sino que debemos efectuar lecturas un tanto caóticas, en las que integramos al proceso de lectura elementos que no necesariamente son contiguos o cercanos. El desafío de la lectura es, en consecuencia, vincular elementos lingüísticos con recursos no lingüísticos, pues en este vínculo se configura el diseño (Kress, 2000; Williamson, 2005).

En cuanto al proceso de lectura en el ámbito multimodal, Kress, Leite-Garcia y Van Leeuwen (2001) proponen un modelo en que se distinguen algunos aspectos asociados al espacio visual, como son las 
dualidades Real/Ideal (arriba y abajo) y lo Dado/ Nuevo (derecha a izquierda) respectivamente, con lo que se configuran cuatro cuadrantes:

De acuerdo a la Figura 2, los autores proponen que, según la tradición lectora occidental fundada en la cultura visual y estética de Europa occidental, el dominio de lo real corresponde a la sección inferior del espacio y sus significaciones apuntan al aquí y ahora o a la experiencia concreta. El dominio de lo ideal puede significar distancia en el tiempo (pasado o futuro) o bien aludir a los anhelos o deseos ideales.

Por su parte, en la distinción en el eje vertical entre lo dado y lo nuevo, la primera apunta a lo que se considera conocido o lo que se da por sentado; mientras que la segunda distinción -lo nuevo- apunta a lo novedoso, lo que se considera una instancia de lo dado. Esta distinción tiene su correlato en la organización discursiva donde la progresión temática de temas y remas se construye a partir del juego entre información dada o conocida e información nueva, lo cual otorga distintos grados de dinamismo comunicacional al discurso (Álvarez, 2001). En síntesis, la dualidad vertical abajo-arriba está marcada por parámetros ontológicos, mientras que la distinción derecha-izquierda está determinada por la calidad de la información que se entrega en el espacio visual (Kress, Leite-Garcia \& Van Leeuven, 2001).

La división horizontal y vertical ya señalada está vinculada al interés del productor del discurso y el tipo de recurso o material que ubica dentro del espacio visual está determinado culturalmente por el interés de quien diseña la estructura (Kress, Leite-Garcia\& Van Leeuven, 2001). Resulta interesante destacar que Kress y van Leeuwen (1996) descubren que al dividir el espacio visual de esta forma, nos encontramos con la figura de la Cruz, que constituye un símbolo espacial fundamental en la cultura occidental (p. 207).

\section{Análisis}

A continuación se presentan algunas estrategias de alfabetización visual a partir de aplicaciones de los modelos antes descritos. Cabe señalar que este análisis constituye una expresión particular de procesos de semiosis ilimitada (Eco, 1979) y, por tanto, cada lectura aportará otros sentidos posibles en la interpretación de este discurso.

\section{Aplicación del modelo Magariños-Peirce}

En este apartado se aplicará el cuadro de análisis de Magariños - Peirce que fue descrito y ejemplificado en la sección 2.3 a un aviso publicitario de la bebida Cola-Cao, en Figura 3. En cada casilla del cuadro, que se ilustra en la Figura 4 se completará con el signo correspondiente advertido en el aviso publicitario de manera de ir fragmentando el discurso publicitario y estableciendo relaciones entre los recursos semióticos que lo conforman.
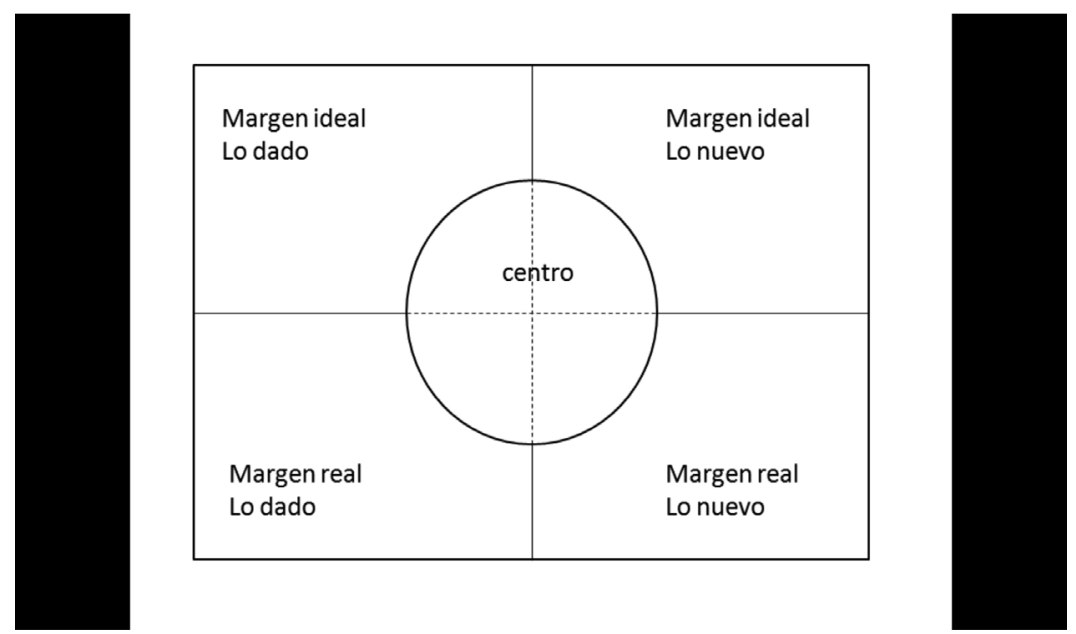

Figura 2. Espacio visual en la semiótica visual occidental.

(Kress, Leite-Garcia, Van Leeuwen, 2001: 395 y Kress y van Leeuwen, 1996: 197) 


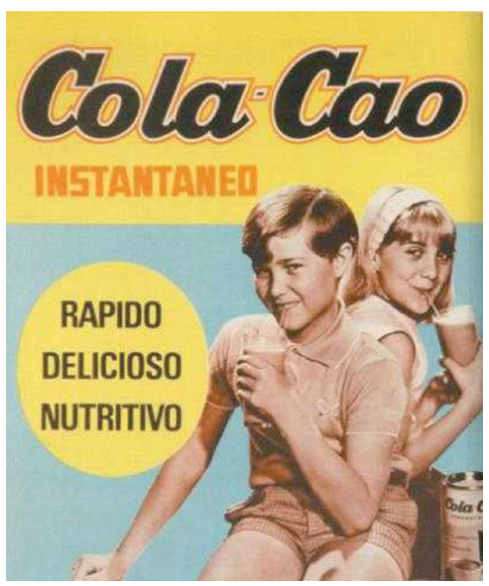

Figura 3. Texto multimodel publicitario

Aplicación del Modelo de Kress, LeiteGarcia y Van Leeuwen

En la composición de este texto multimodal el valor de la información se distribuye en los ejes inferior/superior e izquierda/derecha, creando como lo indica la Figura 2 cuatro cuadrantes.

En el cuadrante inferior izquierda, que corresponde a lo dado/real, se aprecian enmarcados en un óvalo, en formato textual, las cualidades concretas del producto: rápido, delicioso y nutritivo.

En el cuadrante superior izquierda, de lo ideal/dado, se ubica también en formato textual una parte del nombre del producto, Cola, que idealmente se debería asociar con otro producto de éxito reconocido, Coca-Cola; además, aparece la palabra "instantáneo" asociada a un valor conocido de la vida contemporánea: la inmediatez y rapidez como ideales, todo enfatizado con un marco de color amarillo.

En el cuadrante inferior derecho, de lo real/nuevo, se ubican los cuerpos de dos niños, siendo el del niño más prominente que el de la niña, ambos exhibiendo un físico saludable. En el extremo derecho aparece, casi invisible, el envase del producto, como información nueva. La prominencia del nombre del producto en la parte superior del texto ya ha captado la mirada y el envase repite esta información, pero ahora en contexto, que es lo nuevo.

El cuadrante superior derecha, de lo ideal/nuevo, constituye el foco semántico más productivo de este texto, donde se ubica la promesa y la novedad del producto.
La promesa es la felicidad, buena salud y bienestar de los niños, a quienes se los alimenta con un producto de fácil (instantáneo) preparación. La novedad es la segunda parte del nombre del producto, Cao, que, aunque aparece asociado a Coca-Cola, despeja dudas y ahora se asocia al ingrediente principal de la bebida, el cacao.

Por último, cabe destacar los significados nacionalistas de los dos colores dominantes (y que en posteriores ediciones del producto se concretan en el color de la tapa y del envase): amarillo y rojo, de la bandera española.

\section{Conclusiones}

En general, si se compara la aplicación de los modelos, se puede afirmar que mientras el modelo de Magariños-Peirce rescata los signos y sus significaciones dejando de lado la ubicación de esos elementos dentro del espacio visual, la propuesta de Kress y van Leeuwen recoge la disposición de los elementos dentro del espacio visual, ofrece una organización o estructura para el análisis de la combinación texto e imagen y, por tanto, se hace cargo del diseño del discurso.

Por otra parte, si bien el modelo de Magariños-Peirce podría resultar complejo en su aplicación en aula, como se evidenció en aplicaciones preliminares con estudiantes universitarios, ofrece en sus dimensiones de forma, existencia y valor mayores posibilidades de exploración de los sentidos que construyen los textos multimodales y, por lo tanto, podría ser usado para distinguir la complejidad intrínsica en el diseño de los estos textos.

Podemos nuevamente citar a Kress y Van Leeuwen con palabras que muy bien resumen los propósitos de 


\begin{tabular}{|c|c|c|c|}
\hline \multirow{5}{*}{ FORMA } & FORMA & EXISTENCIA & VALOR \\
\hline & CUALISIGNO & ÍCONO & RHEMA \\
\hline & Forma de la forma & Existencia de la forma & Valor de la Forma \\
\hline & $\begin{array}{l}\text { Cualidades que se entienden } \\
\text { como signos }\end{array}$ & $\begin{array}{l}\text { Las formas visuales de objetos } \\
\text { o comportamientos representa- } \\
\text { dos. Formas perceptibles. }\end{array}$ & $\begin{array}{l}\text { Representación visual de un } \\
\text { aspecto o estímulo no visual. }\end{array}$ \\
\hline & $\begin{array}{l}\text { En el aviso se advierten cualida- } \\
\text { des visuales como los colores: } \\
\text { el café que alude al producto } \\
\text { promocionado, el amarillo del } \\
\text { círculo que contiene los atribu- } \\
\text { tos del producto, el negro del } \\
\text { logotipo y el celeste de fondo. }\end{array}$ & $\begin{array}{l}\text { Las imágenes de ambos niños } \\
\text { protagonistas del mensaje pu- } \\
\text { blicitario. Las posturas faciales } \\
\text { que se aprecian en los persona- } \\
\text { jes del aviso. } \\
\text { El tarro y los vasos }\end{array}$ & $\begin{array}{l}\text { El color café de la ropa y de la } \\
\text { piel de los niños es representa- } \\
\text { tivo del producto llamado Cola } \\
\text { Cao que es chocolate; por lo } \\
\text { tanto, un aspecto visual, el color } \\
\text { café, alude al sabor del choco- } \\
\text { late, o sea, al sentido del gusto }\end{array}$ \\
\hline \multirow{5}{*}{ EXISTENCIA } & FORMA & EXISTENCIA & VALOR \\
\hline & SINSIGNO & ÍNDICE & DICISIGNO \\
\hline & Forma de la existencia & Existencia de la existencia & Valor de la existencia \\
\hline & $\begin{array}{c}\text { Conductas o representacio- } \\
\text { nes de formas de existencia. } \\
\text { Todo lo que se perciba como } \\
\text { conducta. }\end{array}$ & $\begin{array}{l}\text { Objetos, conductas que repre- } \\
\text { sentan a otras conductas. Exige } \\
\text { una existencia material. }\end{array}$ & $\begin{array}{l}\text { Representación de todo lo que } \\
\text { constituye el contexto de la } \\
\text { representación. }\end{array}$ \\
\hline & $\begin{array}{l}\text { Los niños están bebiendo el } \\
\text { producto y sus rostros transmi- } \\
\text { ten placer y satisfacción. }\end{array}$ & $\begin{array}{l}\text { El envase del producto que se } \\
\text { puede apreciar en el extremo in- } \\
\text { ferior derecho del aviso, junto a } \\
\text { los niños quienes -al parecer- lo } \\
\text { esconden o protegen }\end{array}$ & $\begin{array}{l}\text { Los signos del aviso publicita- } \\
\text { rios se enmarcan dentro de un } \\
\text { contexto en el cual el propio } \\
\text { aviso tiene la estructura y la for- } \\
\text { ma del envase del producto. Se } \\
\text { puede percibir que los diversos } \\
\text { signos del aviso aparecen den- } \\
\text { tro de un signo mayor: el envase } \\
\text { del producto. }\end{array}$ \\
\hline \multirow[b]{5}{*}{ VALOR } & FORMA & EXISTENCIA & VALOR \\
\hline & LEGISIGNO & SÍMBOLO & ARGUMENTO \\
\hline & Forma del Valor & Existencia del Valor & Valor del Valor \\
\hline & Connotaciones tipográficas & $\begin{array}{c}\text { Lo que representa el signo en el } \\
\text { plano cultural. Es el significado } \\
\text { atribuible. }\end{array}$ & $\begin{array}{l}\text { La representación de los } \\
\text { valores sociales vigentes en de- } \\
\text { terminada comunidad. Valores } \\
\text { culturales. }\end{array}$ \\
\hline & $\begin{array}{l}\text { La fuente tipográfica del logo- } \\
\text { tipo es cursiva, es la típica letra } \\
\text { cuidada de quien está recién } \\
\text { aprendiendo a escribir, o sea, ni- } \\
\text { ños, los receptor es objetivo del } \\
\text { producto. Además el contorno } \\
\text { de la letra está enmarcado, lo } \\
\text { que se percibe como irradiación } \\
\text { de energía. } \\
\text { La instantaneidad, a su vez, está } \\
\text { dada por el contraste cromático } \\
\text { de la tipografía de la palabra } \\
\text { INSTANTANEO. La tipografía } \\
\text { del nombre del producto imita } \\
\text { la de un producto ampliamen- } \\
\text { te conocido; Coca Cola. Doble } \\
\text { referencialidad: tipografía y } \\
\text { nombre muy similar a producto } \\
\text { conocido }\end{array}$ & $\begin{array}{l}\text { Los niños simbolizan la inge- } \\
\text { nuidad propia de la infancia. } \\
\text { El color celeste de fondo no es } \\
\text { casual: representa los atributos } \\
\text { propios de lo celestial, tiene } \\
\text { una connotación religiosa en la } \\
\text { tradición Judeo Cristiana. Jun- } \\
\text { to con el rosado, el celeste es } \\
\text { uno de los dos colores con que } \\
\text { tradicionalmente se viste a los } \\
\text { bebés. El color amarillo, por su } \\
\text { parte, es propio del aura de los } \\
\text { santos y en el aviso es el color } \\
\text { del círculo que contiene los atri- } \\
\text { butos del producto, círculo que } \\
\text { se asemeja a un globo propio de } \\
\text { los utilizados en los cómics. }\end{array}$ & $\begin{array}{l}\text { Los valores culturales difundi- } \\
\text { dos por un aviso publicitario } \\
\text { dependen de la época en la que } \\
\text { éste se difunde. Los signos que } \\
\text { conforman el mensaje transmi- } \\
\text { ten: inocencia infantil, salud, } \\
\text { placer, satisfacción, energía; } \\
\text { en definitiva se rescatan valo- } \\
\text { res asociados a la infancia o } \\
\text { la infancia como un valor en sí } \\
\text { misma. }\end{array}$ \\
\hline
\end{tabular}

Figura 4. Cuadro de analisis de acuerdo a modelo de Magariños 
este trabajo de aplicación de estrategias de alfabetización visual crítica:

\begin{abstract}
Si vamos a entender la manera por la cual importantes instituciones productoras de textos, como los medios de comunicación, la educación y la literatura infantil, crean sentido del mundo y participan en el desarrollo de nuevas formas de estratificación social, ya no es suficiente una teoría del lenguaje sino que tiene que complementarse con teorías que puedan hacer explícitos los principios de la nueva alfabetización visual y describir, por ejemplo, el papel de la diagramación en el proceso de semiosis social que ocurre en las páginas de los textos producidos por estas instituciones (Kress y Van Leeuwen, 1996, p. 186).
\end{abstract}

Sin duda, uno de los peligros de la aplicación de estos modelos es caer en el sobre uso de un metalenguaje (que Chomsky ha denominado "posturing" y Renkema (1999) "una gris red de conceptos críticos") alejado de fines pedagógicos, para lo cual es importante tener en cuenta la gradación de las actividades. El primer paso es hacer explícitos los conocimientos y creencias que los estudiantes traen consigo con respecto a la dimensión visual en la creación de significados, donde se puede centrar la discusión en textos multimodales de uso cotidiano para luego introducir aspectos más complejos del metalenguaje de la semiótica social.

En la clase de lenguas extranjeras o indígenas estas actividades permiten hacer implícito el aprendizaje del código lingüístico al centrar, en primer lugar, la atención en la dimensión visual y, luego, en sus relaciones y aportes al significado lingüístico. A su vez, permite la discusión de problemas de interculturalidad al comparar las distintas valoraciones asignadas culturalmente a los aspectos no verbales de la comunicación lingüística.

\section{Referencias}

Álvarez, G. (2001). Textos y discursos. Introducción a la lingüística del texto. Concepcion: Editorial Universidad de Concepción.

Araya, C. (2011). Análisis crítico de tres afiches de la campaña contra la violencia hacia la mujer Maricón es el que maltrata a una mujer.EnContextos No 25.Santiago, UMCE. Pp 13-25.

Bamford, A. (2007). The visual literacy white paper.University of TechnologySydney. Disponible en Internet y accesado el 10 de octubre de 2012 desde: http://www.adobe.com/uk/education/ pdf/adobe visual literacy_paper.pdf.
Barragán, R. \& Gómez, W. (2012). El lenguaje de la imagen y el desarrollo de la actitud crítica en el aula: propuesta didáctica para la lectura de signos visuales, IKALA, vol. 17, N 1, pp. 81-93.

Braden, B. D., \& Hortin, J. A. (1982). Identifying the theoretical foundations of visual literacy.En International Visual Literacy Association. (ERIC Document Reproduction Service No ED 228980.) Reprinted in Journal of Visual/Verbal Languaging 2 (2), 37-42.

Clavijo, A., Quintana, A. \& Quintero, L. (2011). Enseñanza del inglés y medio digitales. Nuevos retos y posibilidades para la escuela. Bogotá: Universidad Distrital Francisco José de Caldas.

Clavijo, A., \& Quintana, A.(2004). Maestros y estudiantes escritores de hiperhistorias. Bogotá: Universidad Distrital Francisco José de Caldas.

Cope, B. EKalantzis, M. (Eds). (2000). Multiliteracies. Literacy learning and the design of social futures. London: Routledge.

Eco, U. (1979). Tratado de Semiótica General. Barcelona: Lumen.

Fairclough, N. EWodak, R. (2001). Análisis crítico del discurso. En Van Dijk, T. (comp.) El Discurso como interacción Social, Barcelona: Gedisa. (367-404).

Farías, M. (2008). "El ciberlecto de las salas de chateo: ċconversación escrita o escritura conversada?" En Forma y Función, № 21, pp. 347-360.

Farías, M. (2008b). Entrevista a GuntherKress. En M. Farías E K.Obilinovic (Eds). Aprendizaje multimodal/Multimodal learning. Santiago: PUBLIFAHU USACH. (pp. 15-20).

Farías, M. \& Orrego, R. Developingcritical digital literacy in Chileanlanguage education. EnProceedings of World Conference on Educational Multimedia, hypermediaand Telecommunications. Chesapeake, VA: AACE. 2008. (pp. 2571-2576)

Freire, P. (1970). Pedagogía del oprimido. New York: Herder E Herder.

Gee, J.P. (2004). Lo que nos enseñan los videojuegos sobre el aprendizaje y el alfabetismo. Andalucía: Aljibe.

Hernández, F. \& Quintero, A. (2005). Un espacio virtual para la mitología de la enseñanza del inglés. Bogotá: Universidad Distrital Francisco José de Caldas.

Klein, N. (2002). No Logo: el poder de las marcas. Barcelona: Paidos.

Kress, G. R. (1997). Visual and verbal modes of representation in electronically mediatedcommunication: the potentials of new forms of text. In I. Snyder (Ed.) Page toscreen. London: Routledge. (51-53). 
Kress, G. (2000). Design and transformation: New theories of meaning. In B. Cope E M. Kalantzis (Eds.), Multiliteracies: Literacy learning and the design of social futures. London: Routledge. (pp. 153- 161).

Kress, G. (2003).Literacy in the new media age.New York: Routledge.

Kress, G. E van Leeuwen, T. (1996). Reading images: The grammar of visual design. London: Routledge.

Kress, G. R. E van Leeuwen, T. (2001).Multimodal discourse: The modes and media of contemporary communication. London: Edward Arnold.

Kress, G; Leite-García, R.; van Leeuwen, T. (2001). Semiótica discursiva en Van Dijk(Comp). El Discurso como Estructura y Proceso. Barcelona: Gedisa. (373-416).

Lomas, C. (1994). La comunicación publicitaria y Guía para el comentario de textos publicitarios en La enseñanza de la lengua y el aprendizaje de la comunicación.Gijón: Ediciones Trea.

Loyo, A. (2001). Nuevas tecnologías y lectura de hipertextos. Una propuesta constructivista de comprensión de textos e hipertextos. Rio Cuarto, Argentina: Universidad Nacional de Rio Cuarto.

Magariños de Morentin, J. (1991). El mensaje publicitario. Buenos Aires: Edicial. (2 edición).

Martinec, R. y Salway, A. (2005). A system for image-text relations in new (and old) media, in Visual Communication vol. 4, pp. 337-371.

Méndiz Noguero, A. (2007). Diferencias conceptuales entre publicidad y propaganda: una aproximación etimológica. enQuestiones Publicitarias, vol. I, $\mathrm{n}^{\circ} 12$, , pp. 43-61.

Muñoz, D. (2008). Assessment of multimodal discourse: theoretical and technical problems. En M. Farías \& K. Obilinovic (Eds). Aprendizaje multimodal/Multimodal learning. Santiago: PUBLIFAHU USACH. (pp. 111-118).

Pereira, F. y González, G. (2011). Análisis descriptivo de textos escolares de Lenguaje y Comunicación. Literatura y Lingüística No24, 161-182.
Pineda Cachero, A. (2007). Propaganda y publicidad comercial: un principio diferenciador en Questiones Publicitarias, vol. I, $\mathrm{n}^{\circ}$ 12, pp. 107-128.

Renkema, J. (1999). Introducción a los estudios sobre el discurso. Barcelona: Gedisa.

Rueda, R. E Quintana, A. (2007). Ellos vienen con el chip incorporado. Aproximación a la cultura informática escolar. Bogotá: Universidad Distrital Francisco José de Caldas.

Saussure, F. (1945). Curso de Lingüística General. Buenos Aires: Losada. Disponible en:https://docs.google.com/file/d/0B3Nn M3au45jhMDEzNThjNmUItYTE2OCOOMjY0LWEXMWItNmJmNjYwNzkOYzk4/edit

Sexe, N. (2004). Diseño.Com. Buenos Aires, Argentina: Editorial Paidós.

Turkle, S. (1995). Life on the screen: identity in the age of Internet. New York, Simon and Schuster.

Unsworth, L. (2006). Towards a metalanguage for multiliteracies education: Describing the meaning-making resources of language-image interaction. English Teaching: Practice and Critique, 5 (1), 55-76.

Unsworth, L. (2008). Multiliteracies and metalanguage: describing image/text relations as a resource for negotiating multimodal texts, in Coiro, J. et al (eds). Handbook ofresearch on new literacies. New York: Lawrence Earlbaum, pp. 377-405.

Van Dijk, T. (1999). El Análisis Crítico del Discurso. En Anthropos (Barcelona), 186, pp. 23-36.

Walsh, M. (2006). Reading visual and multimodal texts: how is 'reading' different? Australian Journal of Language and Literacy, Vol. 29, No 1, 24-37.

Williamson, R. (2005). ¿A qué le llamamos discurso en una perspectiva multimodal? Los desafíos de una nueva semiótica. Actas del Encuentro de ALED, PUC. Disponible en: http://www. congresoaled2005.puc.cl/fset actas.html.

Wenger, E. (2007).Communities of Practice: Learning, Meaning, and Identity. New York: Cambridge University Press,

Zamora, F. (2006). Filosofía de la imagen. Lenguaje, Imagen y Representación. México, DF: Universidad Autónoma de México. ENAP.

THE AUTHORS

MIGUEL FARÍAS holds a Master of Arts in Linguistics from Ohio University, and a Ph.D. from the Catholic University of America, US. He is Associate Dean for Research and Graduate studies at the Faculty of Humanities, Universidad de Santiago de Chile.

CLAUDIO ARAYA SEGUEL is a teacher of Spanish Education and holds a Master's in Sociolinguistics of American Spanish. He teaches at Universidad de Santiago de Chile and at Universidad Metropolitana de Ciencias de la Educación. 